\title{
Fibrocytes Ameliorate Acute Lung Injury
} by Decreasing Inflammatory Cytokine and Chemokine Levels and Reducing Neutrophil Accumulation in the Lung

\author{
Wenlin Tai ${ }^{\mathrm{a}} \quad$ Yiheng $\mathrm{Xu}^{\mathrm{a}} \quad$ Jiawei Ding ${ }^{\mathrm{a}}$ Hanxin Wu $\mathrm{u}^{\mathrm{a}}$ Ming Du $\mathrm{u}^{\mathrm{a}} \quad$ Xiaoyuan $\mathrm{Qu}^{\mathrm{a}}$ \\ Ling Gao Jinyu Lia Zhaoxing Dong ${ }^{\mathrm{b}}$
}

aDepartment of Clinical Laboratory, Yunnan Molecular Diagnostic Center, The Second affiliated hospital of Kunming Medical University; ${ }^{b}$ Department of Respiration, The Sencond Affiliated Hospital of Kunming Medical University, Kunming, China

\section{Key Words}

Acute lung injury (ALI) - Fibrocytes - Lipopolysaccharide (LPS) - Myeloperoxidase (MPO) • Macrophage inflammatory protein 2 (MIP-2)

\begin{abstract}
Background/Aims: Acute lung injury (ALI) remains a severe disease that threatens human life around the world. To decrease the mortality of ALI and improve ALI treatment efficacy, the development of more ALI treatments is urgently needed. Whether fibrocytes directly participate in ALI has not been studied. Therefore, a mouse model of ALI was induced with lipopolysaccharide (LPS). Methods: Fibrocytes were harvested from peripheral blood mononuclear cells of bleomycin mice and identified by using flow cytometry to detect the expression of molecular makers. The fibrocytes were injected for the treatment of acute lung injury mice. The curative effects were evaluated by using ELISA to determine the cytokines (including TNF- $\alpha$, IL- 6 and IFN- $\gamma$ ) concentrations in bronchoalveolar lavage fluid (BALF) supernatant. Results: The concentrations of cytokines such as tumor necrosis factor- $\alpha$ (TNF- $\alpha$ ), interleukin-6 (IL-6), and interferon- $\gamma$ (IFN- $\gamma$ ) were increased in mice with ALI induced with LPS. The concentrations of TNF- $\alpha$, IL- 6 , and IFN- $\gamma$ as well as their mRNA and protein expression levels were decreased by administration of fibrocytes. The effect of fibrocytes in ameliorating ALI was time dependent. LPS treatment induced an increase in myeloperoxidase (MPO) activity, whereas the fibrocyte treatment caused inhibition of MPO activity as well as expression of the neutrophil-chemoattractant chemokine macrophage inflammatory protein 2 (MIP-2). Conclusion: Taken together, these data suggest that fibrocytes ameliorated ALI by suppressing inflammatory cytokines and chemokines as well as by decreasing the accumulation of neutrophils in the lung.

W. Tai and Y. Xu contributed equally to this work.




\section{Introduction}

Acute lung injury (ALI) remains a life-threatening disease manifesting as an acute inflammatory response of the lung and resulting in disruption of lung endothelial and epithelial barriers [1-3]. Direct injury to the lung (such as in pneumonia or aspiration) and indirect mechanisms (such as sepsis or burn) may lead to the occurrence of ALI [4]. Typical symptoms of ALI are dyspnea, tachypnea, dry cough and retrosternal discomfort [5, 6]. The present therapeutic approaches for ALI include supportive care, ventilator support, pharmacological treatments and mesenchymal stem cells (MSCs) [2, 7-9]. ALI can develop into more severe acute respiratory distress syndrome (ARDS) or multiple organ dysfunction syndrome (MODS), and the incidence and mortality of ALI remains high around the world $[7,10]$. Therefore, developing novel therapies to treat ALI and improve the clinical outcomes is urgently necessary.

Lipopolysaccharide (LPS) is a key component of the cell wall of gram-negative bacteria that can induce pulmonary and systemic infection $[3,10,11]$. LPS participates in initiating the inflammatory response by binding to its receptors. LPS exposure can result in systemic inflammatory response syndrome (SIRS) and ALI $[12,13]$. Therefore, LPS has been used to establish a rat ALI model in various studies. Circulating fibrocytes are derived from bone marrow and circulate within the bloodstream, and these cells are characterized by hematopoietic markers such as CD34, leukocyte markers such as CD45, and the fibroblast products $\alpha$-smooth muscle actin ( $\alpha$-SMA) and collagen 1 (Col-1) [14]. Circulating fibrocytes migrate to inflammatory or injured sites and participate in tissue healing or repair under inflammatory conditions [15-17]. Circulating fibrocytes release vascular endothelial growth factor (VEGF), cytokines and growth factors as well as activate fibroblasts to help the repair process $[15,18]$. Circulating fibrocytes can differentiate into fibroblasts, osteoblasts and adipocytes [19, 20]. Fibroblasts are important cells that participate in fibroproliferation and wound healing [21]. Previous results have shown that fibroproliferation is a stereotypical part of the normal repair process in ALI/ARDS, which is characterized by intra-alveolar accumulation of fibroblasts and collagen deposition [21-24]. Other reports have shown that excessive fibroproliferation is associated with poorer outcomes [23, 25]. Fibrocytes participate in bleomycin models of pulmonary fibrosis [26]. Fibrocytes exist in bronchoalveolar lavage fluid (BALF) and BAL blood of patients with IPF as well as the BALF of patients with ARDS, which increases mortality in ARDS patients [27]. As mentioned above, fibrocytes are closely associated with lung diseases and inflammation [16, 28]. Whether fibrocytes directly participates in ALI has not been clearly demonstrated.

To study the function of fibrocytes in ALI, LPS was used to induce ALI in mice. Then, isolated fibrocytes were administered to mice with ALI, and the efficacy of fibrocytes in treating ALI was evaluated.

\section{Materials and Methods}

\section{Isolation of circulating fibrocytes}

Fibrocytes were harvested from peripheral blood mononuclear cells (PBMC) of bleomycin mice according to previously described methods [17]. After centrifugation, the non-adherent cells were removed. Then the remained adherent cells were cultured for 10 days and the morphology of cells was observed. To confirm that the cells were indeed fibrocytes, mesenchymal markers including collagen-1, hematopoietic markers such as CD34, leukocyte markers such as CD45 and the fibroblast products $\alpha$-smooth muscle actin $(\alpha-S M A)$ and myeloid markers were analyzed. In addition, wound healing assays were performed according to previous reports to study the therapeutic effect of isolated fibrocytes [29].

\section{Animals}

The experimental procedures were carried out according to the Guide for the Care and Use of Laboratory Animals (8 ${ }^{\text {th }}$ edition) [30]. Specific pathogen-free (SPF) male BALB/c mice (16-20 g) aged 6 to 8 weeks were fed under SPF conditions at room temperature (12 h dark and light cycles). 


\section{Cellular Physiology Cell Physiol Biochem 2017;44:1526-1536

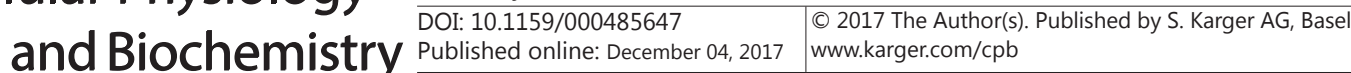 \\ Tai et al.: Effects of $\mathrm{Cfb}$ in ALI}

LPS-induced ALI mouse model

Forty male BALB/c mice were randomly divided into 4 groups: Control, LPS, LPS+Fb $24 \mathrm{~h}$, and LPS+Fb $72 \mathrm{~h}$. Based on previously published methods, ALI was induced by LPS (Sigma-Aldrich, USA) via intratracheal injection. In brief, mice were anesthetized with $30 \mathrm{mg} / \mathrm{kg}$ pentobarbital sodium and then treated with $10 \mu \mathrm{g}$ of LPS. The mice in the Control group were administered sterile saline instead. Then, 10 minutes after LPS injection, mice were treated with $\mathrm{Fb}$.

\section{Bronchoalveolar lavage fluid (BALF) and cell counting}

After $72 \mathrm{~h}$, mice were sacrificed after anesthesis with pentobarbitone (50 mg/kg i.p.). BALF was collected by cannulating the upper part of the trachea by lavage 3 times with $1.0 \mathrm{ml}$ of PBS (PH 7.2). The fluid recovery rate was about $90 \%$. Lavaged samples were kept on ice, BALF was centrifuged at $4{ }^{\circ} \mathrm{C}$. The sedimented cells were resuspended in $50 \mu \mathrm{l}$ of PBS and stained with hematoxylin and eosin (H\&E) for cytospin preparation. Total cells, neutrophils, macrophages and lymphocytes were counted in a doubleblinded manner with a hemocytometer.

Determining the concentrations of TNF- $\alpha, I L-6$ and IFN- $\gamma$ in BALF

The BALF supernatant was collected after centrifugation (for $4 \mathrm{~min}$ at $4000 \mathrm{rpm}$ ) and stored at $-80{ }^{\circ} \mathrm{C}$ for cytokine assays. Tumor necrosis factor- $\alpha$ (TNF- $\alpha$ ), interleukin-6 (IL-6), and interferon- $\gamma$ (IFN- $\gamma$ ) levels in BALF were measured by ELISA (R\&D Systems, Minneapolis, MN, USA) according to the manufacturer's protocols.

\section{Lung wet/dry weight ratio (W/D)}

The severity of pulmonary edema was assessed by the wet to dry ratio (W/D). The left lower lungs were weighed and then dehydrated at $60^{\circ} \mathrm{C}$ for $72 \mathrm{~h}$ in an oven [31].

\section{H\&E staining}

The right lower lung of each mouse was fixed in $10 \%$ formalin, embedded in paraffin, cut into $5 \mu \mathrm{m}$ sections, and stained with H\&E to analyze pathological alteration of the lung tissues. The lung injury score was recorded according to previous reports [31]. In brief, a score of 0 represented no damage, 1 represented mild damage, 2 represented moderate damage, 3 represented severe damage, and 4 represented very severe histologic changes.

\section{Reverse transcription polymerase chain reaction (RT-PCR) and Western blotting (WB)}

The mRNA expression levels of TNF- $\alpha$, IL- 6 and IFN- $\gamma$ were determined by RT-PCR. cDNA was synthesized by using PrimeScript II 1st Strand cDNA Synthesis Kit (Takara, Japan). The primer sequences used for RTPCR were as follows: TNF- $\alpha$ forward primer: 5' ATGAGCACAGAAAGCATGATC 3', TNF- $\alpha$ reverse primer: 5' TACAGGCTTGTCACTCGAATT 3'; IL-6 forward primer: 5' GAGGATACCACTCCCAACAGACC 3', IL-6 reverse primer: 5' AAGTGCATCATCGTTGTTCATACA 3'; IFN- $\gamma$ forward primer: 5' ATGAACGCTACACACTGCATC 3', IFN- $\gamma$ reverse primer: 5' CCATCCTTTTGCCAGTTCCTC 3'; $\beta$-actin forward primer: 5' GGCTGTATTCCCCTCCATCG 3'; $\beta$-actin reverse primer: 5' CCAGTTGGTAACAATGCCATGT 3'. The PCR reactions were carried out in a 7500 Real-time PCR system (Applied Biosystems) and performed under the following thermocycler conditions: $95{ }^{\circ} \mathrm{C}$ for $20 \mathrm{~s}$ followed by 40 cycles of $95{ }^{\circ} \mathrm{C}$ for $3 \mathrm{~s}$ and $60{ }^{\circ} \mathrm{C}$ for $30 \mathrm{~s}$. Raw data from all samples were collected and normalized to $\beta$-actin. The gene expression levels of TNF- $\alpha$, IL- 6 and IFN- $\gamma$ were calculated using the relative quantification equation $\left(\mathrm{RQ}=2^{-\Delta \Delta \mathrm{ct}}\right)[32]$.

The protein expression of TNF- $\alpha$, IL- 6 and IFN- $\gamma$ was evaluated by WB. Protein concentrations were determined using a BCA Protein Assay Kit (Keygen Biotech). Proteins were separated on 10\% SDSpolyacrylamide gels, electroblotted onto an Immobilon-P transfer polyvinylidene fluoride membrane 20 (Millipore, USA), detected with a rabbit anti-mouse TNF- $\alpha$ multiclonal antibody (ab9635, 1:2000, abcam, USA), a rabbit anti-mouse IL-6 multiclonal antibody (ab6672, 1: 2, 000, abcam, USA), a rabbit anti-mouse IFN- $\gamma$ multiclonal antibody (ab9635, 1:2000, abcam, USA), or a rabbit anti-mouse $\beta$-actin multiclonal antibody (ab8227, 1:5000, abcam, USA), and then visualized with a commercial Immobilon Western HRP Substrate (WBKLS0500, Millipore, USA) in the dark. 


\section{Cellular Physiology Cell Physiol Biochem 2017;44:1526-1536

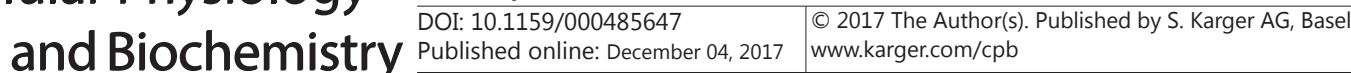 \\ Tai et al.: Effects of $\mathrm{Cfb}$ in ALI}

\section{Myeloperoxidase (MPO) activity assay}

Myeloperoxidase (MPO) activity was determined to assess the accumulation of neutrophils in the lungs. Briefly, the frozen tissue samples were thawed and suspended in 10\% phosphate buffer (pH 6.0) containing $1 \%$ hexadecyltrimethylammonium bromide. The samples were sonicated on ice and centrifuged at $12000 \mathrm{rpm}$ for $15 \mathrm{~min}$ at $4{ }^{\circ} \mathrm{C}$. An aliquot (30 $\mu \mathrm{l}$ ) was transferred into $180 \mu \mathrm{l}$ of phosphate buffer (pH 6.0) containing $0.167 \mathrm{mg} / \mathrm{mL}$ o-dianisidine dihydrochloride and $0.0005 \%$ hydrogen peroxide $\left(\mathrm{H}_{2} \mathrm{O}_{2}\right)$. The absorbance was read at $490 \mathrm{~nm}$. Results are expressed as units of MPO activity per gram of lung tissue.

\section{Statistical analysis}

All statistical analyses were performed with Statistical Package for the Social Sciences (SPSS) 19.0 software. All parameters are presented as means \pm SD. Statistical significance was determined by paired or unpaired Student's t-test in cases of standardized expression data. $\mathrm{P}<0.05$ was considered to indicate a statistically significant difference.

\section{Results}

Identification of circulating fibrocytes in bleomycin-treated mice

To address whether circulating fibrocytes (Fbs) could treat ALI/ARDS, Fbs were first isolated from the peripheral mononuclear cells (PBMCs) of bleomycin-treated mice. The proliferation rate and the morphology of the cells is shown in Fig. $1 \mathrm{~A}$. Until the $5^{\text {th }}$ day after isolation, long spindle-shaped cells with ellipsoid nuclei appeared, and they were considered to be Fb. After culture, most of the cells exhibited a spindle shape and adhered to the bottom of the wells.

Fbs were a distinct population of blood-borne cells and were identified by specific coexpression of several markers, including collagen-1, CD34, CD45, $\alpha$-SMA and myeloid markers. On the $5^{\text {th }}$ day, the percentage of $\mathrm{CD} 45^{+} / \mathrm{Col}-\mathrm{I}^{+}$cells was about $9 \%$, which represented the fibroblast precursors, while no $\alpha-\mathrm{SMA}^{+}$cells were observed at that time point (Fig. 1B \& 1C). The percentage of $\mathrm{CD}^{4} 5^{+} / \mathrm{Col}-\mathrm{I}^{+}$cells was increased at the $10^{\text {th }}$ day, decreased beginning on the $14^{\text {th }}$ day and almost zero at the $21^{\text {st }}$ day. Once $\mathrm{Fb}$ had differentiated, the cells expressed $\alpha$-SMA, a marker of myofibroblasts. The Col- $\mathrm{I}^{+} / \alpha-\mathrm{SMA}^{+}$levels increased during culture, suggesting that cultured $\mathrm{Fb}$ could traffic to injured tissues in response to microenvironmental stimulation.

To identify the therapeutic effects of isolated $\mathrm{Fb}$, a wound-healing test was performed (Fig. 1D). The wound area narrowed by $\sim 50 \%$ at $6 \mathrm{~h}$ after seeding the cells, and the wound gap was nearly covered at $24 \mathrm{~h}$ after seeding cells. These results suggested that the isolated $\mathrm{Fb}$ could differentiate into therapeutic cells in vitro.

Fb ameliorates pulmonary inflammation and pulmonary edema in LPS-induced acute lung injury

H\&E staining was utilized to observe pathological changes in the lung tissues. As shown in Fig. 2A, the lung tissues from the LPS group demonstrated significant pathological alterations, including notable inflammatory cell infiltration, interstitial and intra-alveolar edema and patchy hemorrhaging, and some collapsed alveoli. When pre-treated with Fb, inflammatory cell infiltration was not significantly improved, but the intra-alveolar edema and patchy hemorrhaging were ameliorated remarkably. To evaluate the severity of pulmonary injury, the lung injury score and wet to dry ratio (W/D) were calculated. As shown in Fig. 2B and 2C, both the injury scores and W/D were markedly attenuated by administration of Fb. However, there was still a difference in lung injury scores and W/D between the control group and the $72 \mathrm{~h} \mathrm{Fb}$ group, suggesting that Fb could only partially reverse LPS injury to the lung.

Fb decreases cell counts and inflammatory mediator levels in bronchoalveolar lavage fluid (BALF) following LPS-induced acute lung injury

To further evaluate the anti-inflammatory properties of $\mathrm{Fb}$, cell counts and the levels of inflammatory mediators, including TNF- $\alpha$, IL- 6 and IFN- $\gamma$, in bronchoalveolar lavage 


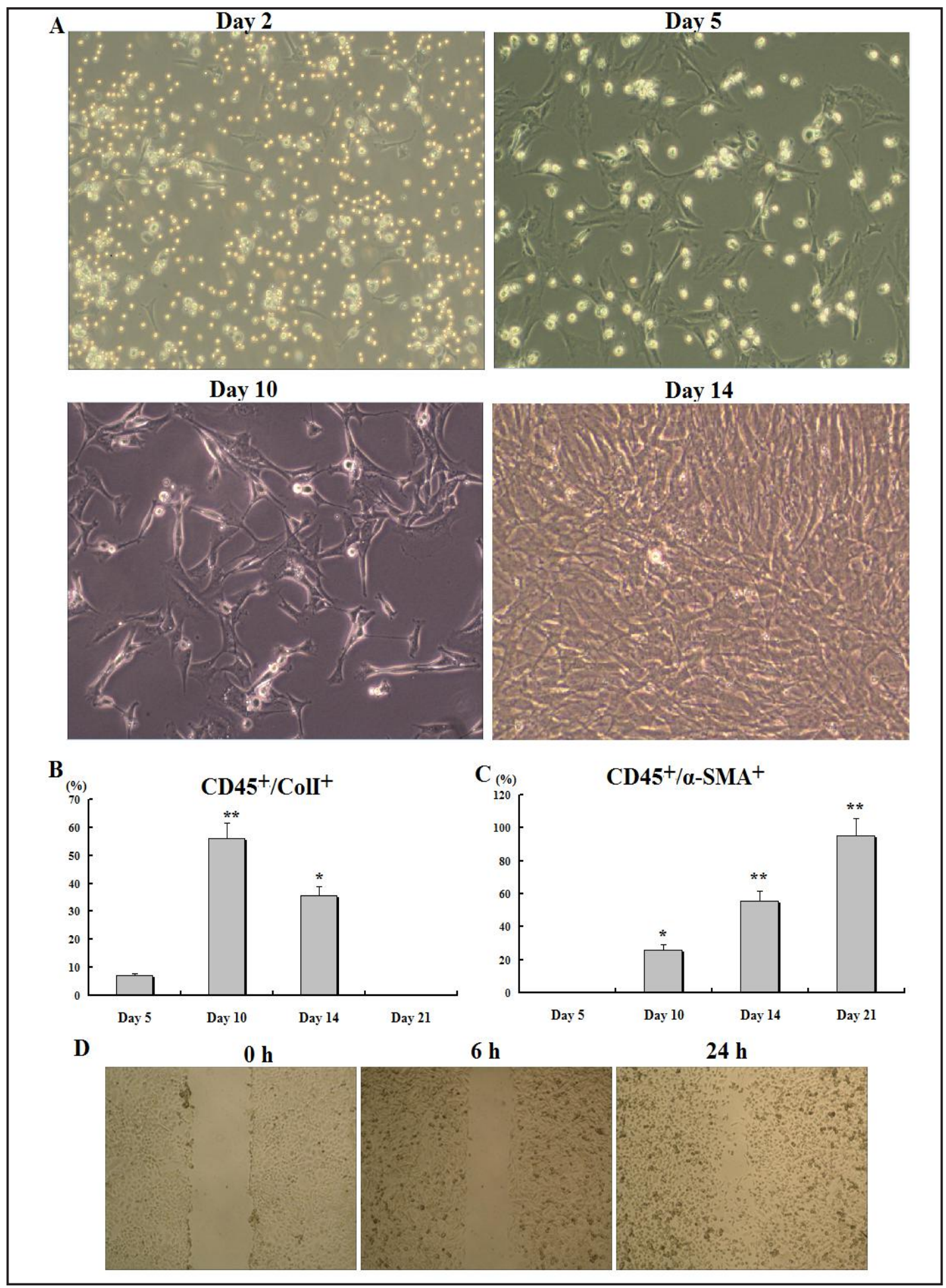

Fig. 1. Identification of circulating fibrocytes in bleomycin-treated mice. A. The cell proliferation rate and cell morphology. B and C. The percentage of $\mathrm{CD} 45^{+} / \mathrm{Col}-\mathrm{I}^{+}$and Col- $\mathrm{I}^{+} / \alpha-\mathrm{SMA}^{+}$cells among fibroblasts $(6$ mice/group). D. Wound healing assay of isolated fibroblasts. The data are presented as the mean \pm SEM. Statistical significance was determined by paired or unpaired Student's t-test. * represented $\mathrm{p}<0.05$ significant difference compared to Day 5 ; ${ }^{* *}$ represented $\mathrm{p}<0.01$ significant difference compared to Day 5. 


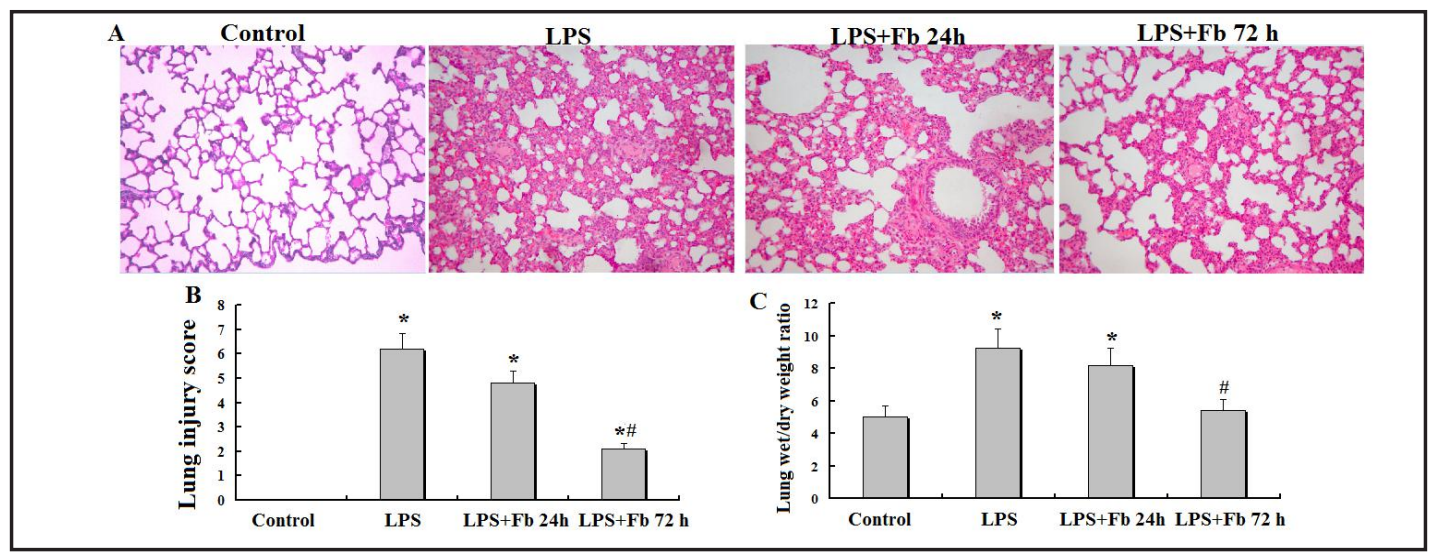

Fig. 2. Fb ameliorate pulmonary inflammation and pulmonary edema in LPS-induced ALI. A. Pathological changes in the lung tissues observed by H\&E staining. B and C. The lung injury score and lung weight/dry weight ratio (W/D) (6 mice/group). The data are presented as the mean \pm SEM. Statistical significance was determined by paired or unpaired Student's t-test. * represented $\mathrm{p}<0.05$ significant difference compared to Control group; \# represented $\mathrm{p}<0.05$ significant difference compared to LPS group.



Fig. 3. Fb decrease cell counts and the levels of inflammatory mediators in bronchoalveolar lavage fluid (BALF) after LPS-induced acute lung injury (6 mice/group). A. The numbers of total cells, neutrophils and macrophages in BALF. B. The levels of TNF- $\alpha$, IL-6, and IFN- $\gamma$ in BALF. C. The levels of TNF- $\alpha$, IL-6, and IFN- $\gamma$ in serum. The data are presented as the mean \pm SEM. Statistical significance was determined by paired or unpaired Student's t-test. * represented p<0.05 significant difference compared to Control group; \# represented $\mathrm{p}<0.05$ significant difference compared to LPS group. 


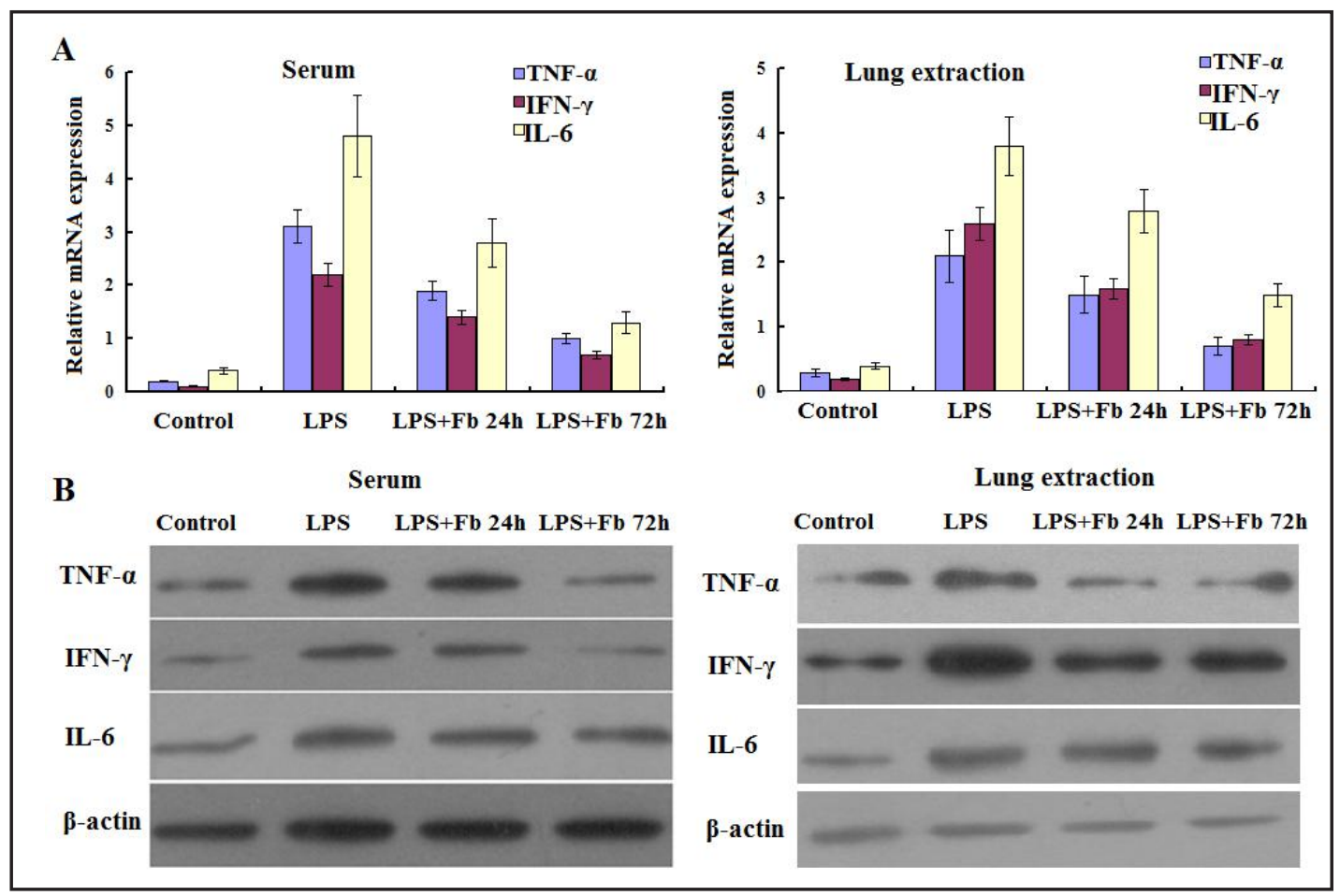

Fig. 4. Effect of Fb pre-treatment on cytokine profiles. A. The mRNA expression levels of TNF- $\alpha$, IL-6, and IFN- $\gamma$ in serum and lung extracts. B. The protein expression levels of TNF- $\alpha$, IL-6, and IFN- $\gamma$ in serum and lung extracts. The data are presented as the mean \pm SEM.

fluid (BALF) were measured. As shown in Fig. 3, the numbers of total cells, neutrophils and macrophages in BALF were significantly increased after LPS stimulation. Fb largely reduced the number of total cells, neutrophils, macrophages in BALF $72 \mathrm{~h}$ after treatment with $\mathrm{Fb}$ (Fig. 3A). However, there were significant differences in the total cells, neutrophils, and macrophages between the control group and the LPS+Fb $24 \mathrm{~h}$ intervention group, which suggested that $\mathrm{Fb}$ could markedly reduce the inflammatory response caused by LPS but could not completely prevent the inflammation. Differences in lymphocyte levels in BALF were not found among all groups. In addition, the levels of TNF- $\alpha$, IL- 6 , and IFN- $\gamma$ in BALF were consistent with the number of neutrophils (Fig. 3B).

To explore the effect of $\mathrm{Fb}$ on serum cytokine profiles, serum samples were collected from LPS or Fb pre-treated mice after intervention. All cytokine levels in serum markedly increased after LPS injection and then decreased after administration of Fb (Fig. 3C). However, the cytokine levels at $24 \mathrm{~h}$ and $72 \mathrm{~h}$ were still higher than those of the control group $(\mathrm{p}<0.05)$. The results were similar to the cytokine levels in BALF.

\section{Effect of Fb pre-treatment on cytokine profiles}

$\mathrm{Fb}$ pre-treatment significantly suppressed neutrophil accumulation in the lung caused by LPS-induced ALI. To demonstrate the effect of $\mathrm{Fb}$ pre-treatment on serum chemokine profiles, the profile of cytokine expression in serum and lung extraction was determined by qPCR and Western blot, and we examined the difference between the control and pre-treatment groups. As shown in Fig. 4, the expression levels of TNF- $\alpha$, IL-6, and IFN- $\gamma$ were elevated in serum and the lung after stimulation with LPS but were suppressed by administration of $\mathrm{Fb}$. The expression levels of these factors at $72 \mathrm{~h}$ were lower than those at $24 \mathrm{~h}$ but still higher than those in the control group. 
Fig. 5. Fb inhibit myeloperoxidase (MPO) activity and chemokine levels following LPS-induced lung injury (6 mice/group). A. Myeloperoxidase (MPO) activity after administration of $\mathrm{Fb}$. B. The levels of MIG (CXCL9), MIP-2 (CXCL2) and RANTES (CCL5) were affected by treatment with $\mathrm{Fb}$. The data are presented as the mean \pm SEM. Statistical significance was determined by paired or unpaired Student's t-test. * represented $\mathrm{p}<0.05$ significant difference compared to Control group; \# represented $\mathrm{p}<0.05$ significant difference compared to LPS group.

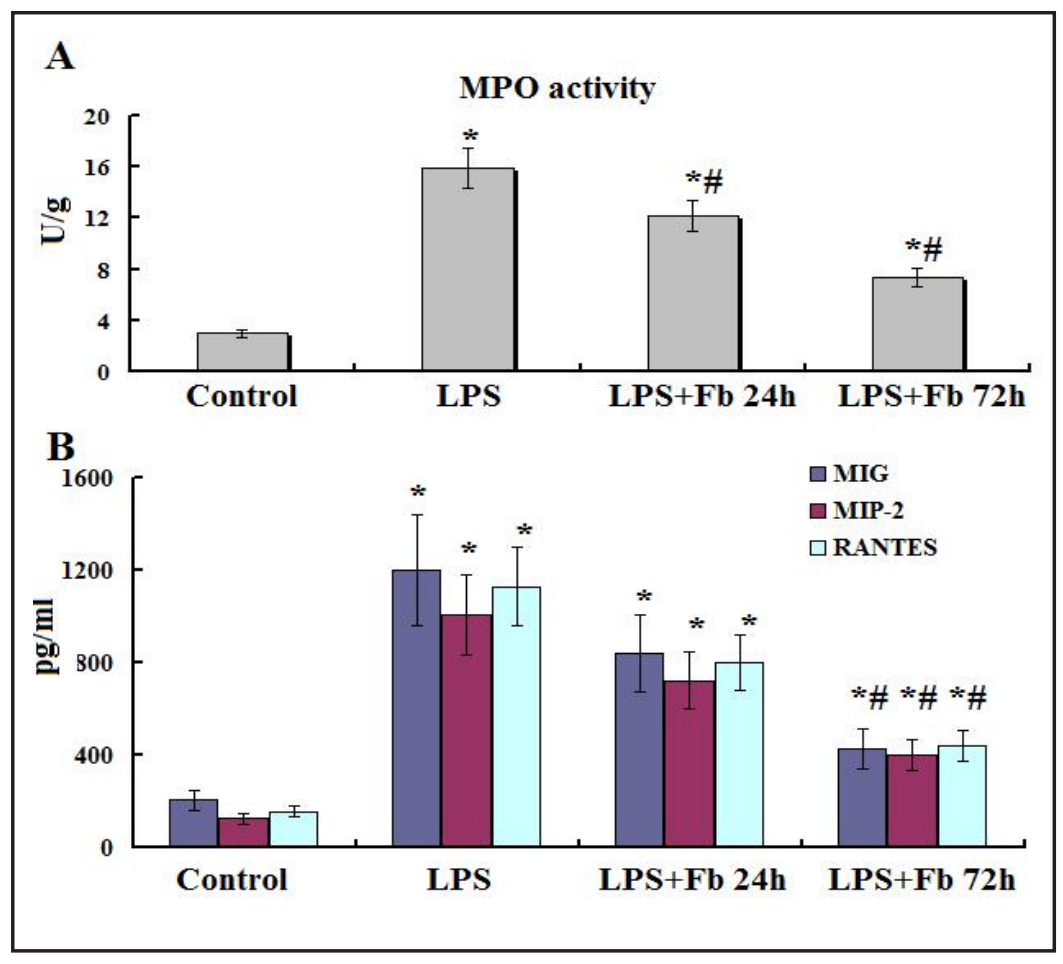

Fb inhibit myeloperoxidase (MPO) activity and chemokine expression following LPSinduced lung injury

Myeloperoxidase (MPO) activity was used to assess the activation and accumulation of neutrophils in lung tissues. After LPS injection, MPO activity was significantly enhanced, and MPO activity was inhibited by treatment with $\mathrm{Fb}$ (Fig. 5A). As shown in Fig. 5B, the levels of MIG (CXCL9), MIP-2 (CXCL2) and RANTES (CCL5) in serum were significantly suppressed by treatment with Fb. Notably, the expression of the neutrophil-chemoattractant chemokine MIP-2 was suppressed. Taken together, our present data suggested that Fb pre-treatment may suppress the expression of inflammatory cytokines and chemokines, resulting in decreased accumulation of neutrophils in the lung.

\section{Discussion}

ALI remains a severe disease that threatens human life around the world and manifests as abnormal gas exchange or chest pain [2]. Pro-inflammatory cytokines such as TNF- $\alpha$, IL-6, and IFN- $\gamma$, which have strong pro-inflammatory activities, are often used as biomarkers of ALI [33-35]. The levels of TNF- $\alpha$, IL-6, and IFN- $\gamma$ are increased in the early phase of ALI [3335]. The activity of myeloperoxidase (MPO), a lung injury marker, can be used to evaluate the accumulation of neutrophils in the lungs [36]. Serum chemokines, such as MIG (CXCL9), MIP-2 (CXCL2) and RANTES (CCL5), are related to lung injury [37-40]. LPS is generally used to induce ALI in mice. To decrease the mortality of ALI and improve ALI treatment, the development of novel treatments for ALI is urgently needed. Fibrocytes are a type of cell that is related to inflammation and wound healing $[15,16]$. Fibrocytes are closely associated with lung diseases and inflammation $[14,16,28,41,42]$. Whether fibrocytes directly participate in ALI has not been studied previously.

Herein, a mouse ALI model was induced with LPS. The concentrations of cytokines such as TNF- $\alpha$, IL-6, and IFN- $\gamma$ were increased in the LPS group compared with the control group and the LPS $+\mathrm{Fb}$ group at the same time points, which was consistent with previous

\section{KARGER}




\section{Cellular Physiology Cell Physiol Biochem 2017;44:1526-1536 \begin{tabular}{l|l|l} 
DOI: 10.1159/000485647 & $\begin{array}{l}\text { O 2017 The Author(s). Published by S. Karger AG, Basel } \\
\text { www.karger.com/cpb }\end{array}$ \\
\hline and Biochemistry
\end{tabular} \\ Tai et al.: Effects of Cfb in ALI}

results [34]. Isolated fibrocytes were administered to mice with ALI, and the concentrations of TNF- $\alpha$, IL-6, and IFN- $\gamma$ were determined. The results showed that the concentrations of TNF- $\alpha$, IL- 6 , and IFN- $\gamma$, as well as their mRNA and protein expression levels, were decreased by fibrocytes. The effect of fibrocyte-mediated amelioration of ALI is time dependent. LPS treatment induced the enhancement of MPO activity, whereas fibrocyte treatment caused the inhibition of MPO activity as well as a reduction in the levels of other serum chemokines such as MIG (CXCL9), MIP-2 (CXCL2) and RANTES (CCL5). These results suggested that fibrocytes could ameliorate the inflammation associated with ALI and repair ALI-mediated injury [43]. Furthermore, the expression of the neutrophil-chemoattractant chemokine MIP-2 was suppressed by administration of Fb. Taken together, these data suggested that fibrocytes ameliorated ALI by suppressing inflammatory cytokines as well as chemokines and decreasing the accumulation of neutrophils in the lung.

Fibrocytes can differentiate into fibroblasts, which are the key cells that participate in fibroproliferation and wound healing $[19,23]$. Fibroproliferation is an important process in ALI, which is considered to be the injury repair process for ALI. ${ }^{15}$ However, many reports have shown that excessive fibroproliferation induces fibrosis of the lung and causes the death of patients with ALI $[21,24]$. In addition, another report showed that the alveolar fibrocyte level can act as an independent predictor of poor outcomes in patients with ALI [27]. Therefore, the function of fibrocytes in ALI needs to be further investigated in future studies.

\section{Conclusion}

Taken together, fibrocytes decreased the levels of pro-inflammatory cytokines such as TNF- $\alpha$, IL- 6 , and IFN- $\gamma$. Furthermore, fibrocyte treatment caused the inhibition of the MPO activity, a reduction in the levels of other serum chemokines such as MIG (CXCL9), MIP-2 (CXCL2) and RANTES (CCL5) as well as chemokines, and a decrease in the accumulation of neutrophils in the lung. Therefore, we conclude that fibrocytes indeed ameliorate ALImediated inflammation and can repair ALI-induced injury.

\section{Disclosure Statement}

The authors declare that there is no conflict of interest associated with this work.

\section{Acknowledgements}

This work was financially supported by National Natural Science Foundation of China (No. 81360262).

\section{References}

$>1$ Mackay A, Al-Haddad M: Acute lung injury and acute respiratory distress syndrome. Critical Care \& Pain 2009;9:152-156.

2 Johnson ER, Matthay MA: Acute Lung Injury Epidemiology, Pathogenesis, and Treatment. J Aerosol Med Pulm D 2010;23:243-252.

3 Mouratis MA, Magkrioti C, Oikonomou N, Katsifa A, Prestwich GD, Kaffe E, Aidinis V: Autotaxin and Endotoxin-Induced Acute Lung Injury. PloS One 2015;10:e0133619.

4 Ware LB, Matthay MA: The acute respiratory distress syndrome. New Engl J Med 2000;342:1334-1349.

5 Zhang HX, Liu SJ, Tang XL, Duan GL, Ni X, Zhu XY, Liu YJ, Wang CN: H2S Attenuates LPS-Induced Acute Lung Injury by Reducing Oxidative/Nitrative Stress and Inflammation. Cell Physiol Biochem 2016;40:1603-1612. 


\section{Cellular Physiology Cell Physiol Biochem 2017;44:1526-1536 \begin{tabular}{l|l|l} 
DOI: 10.1159/000485647 & $\begin{array}{l}\text { O 2017 The Author(s). Published by S. Karger AG, Basel } \\
\text { www.karger.com/cpb }\end{array}$
\end{tabular} \\ Tai et al.: Effects of $\mathrm{Cfb}$ in ALI}

6 Xu S, Xu M, Li GG, Wang C, Song H, Bai J: Early Recruitment of IL-10-Producing B Cells Into Alveoli Improved the Resolution of Acute Lung Injury. Cell Physiol Biochem 2016;38:1752-1760.

7 Luh SP, Chiang CH: Acute lung injury/acute respiratory distress syndrome (ALI/ARDS): the mechanism, present strategies and future perspectives of therapies. J Zhejiang Univ Sci B 2007;8:60-69.

8 Ortiz LA, Gambelli F, McBride C, Gaupp D, Baddoo M, Kaminski N, Phinney DG: Mesenchymal stem cell engraftment in lung is enhanced in response to bleomycin exposure and ameliorates its fibrotic effects. Proc Natl Acad Sci USA 2003;100:8407-8411.

-9 Ortiz LA, Dutreil M, Fattman C, Pandey AC, Torres G, Go K, Phinney DG: Interleukin 1 receptor antagonist mediates the antiinflammatory and antifibrotic effect of mesenchymal stem cells during lung injury. Proc Natl Acad Sci USA 2007;104:11002-11007.

10 Bakowitz M, Bruns B, McCunn M: Acute lung injury and the acute respiratory distress syndrome in the injured patient. Scand J Trauma Resus 2012;20:54-58.

11 Tao Z, Yuan Y, Liao Q: Alleviation of Lipopolysaccharides-Induced Acute Lung Injury by MiR-454 Cell Physiol Biochem 2016;38:65-74.

12 Li S, Ni Z, Cong B, Gao W, Xu S, Wang C, Yao Y, Ma C, Ling Y: CCK-8 inhibits LPS-induced IL-1beta production in pulmonary interstitial macrophages by modulating PKA, p38, and NF-kappaB pathway. Shock 2007;27:678-686.

13 Zhao Y, Zhang M, Xiong RP, Chen XY, Li P, Ning YL, Yang N, Peng Y, Zhou YG: Somatostatin Reduces the Acute Lung Injury of Mice via Increasing the Affinity of Glucocorticoid Receptor. Cell Physiol Biochem 2016;38:1354-1364.

14 Cao T, Rajasingh S, Rajasingh J: Circulating fibrocytes serve as a marker for clinical diagnosis. Ann Trans Med 2016;4:S38.

15 Grieb G, Bucala R: Fibrocytes in Fibrotic Diseases and Wound Healing. Adv Skin Wound Care 2012;1:36-40.

-16 Peng H, Herzog EL: Fibrocytes: emerging effector cells in chronic inflammation. Curr Opin Pharmacol 2012;12:491-496.

17 Abe R, Donnelly SC, Peng T, Bucala R, Metz CN: Peripheral Blood Fibrocytes: Differentiation Pathway and Migration to Wound Sites. J Immunol 2001;166:7556-7562.

18 Yu X, Lin Q, Qin X, Ruan Z, Zhou J, Lin Z, Su Y, Zheng J, Liu Z: ACE2 Antagonizes VEGFa to Reduce Vascular Permeability During Acute Lung Injury. Cell Physiol Biochem 2016;38:1055-1062.

19 Hong KM, Belperio JA, Keane MP, Burdick MD, Strieter RM: Differentiation of human circulating fibrocytes as mediated by transforming growth factor-beta and peroxisome proliferator-activated receptor gamma. J Biol Chem 2007;282:22910-22920.

20 Zhou Z, You Z: Mesenchymal Stem Cells Alleviate LPS-Induced Acute Lung Injury in Mice by MiR-142a-5pControlled Pulmonary Endothelial Cell Autophagy. Cell Physiol Biochem 2016;38:258-266.

-21 Marshall RP BG, Webb S, Puddicombe A, Goldsack N, McAnulty RJ, Laurent GJ: Fibroproliferation occurs early in the acute respiratory distress syndrome and impacts on outcome.pdf. Am J Respir Crit Care Med 2000;162:1783-1788.

-22 Bellingan GJ: The pulmonary physician in critical care * 6 The pathogenesis of ALI/ARDS. Thorax 2002;57:540-546.

23 Garibaldi BT, D’Alessio FR, Mock JR, Files DC, Chau E, Eto Y, Drummond MB, Aggarwal NR, Sidhaye V, King LS: Regulatory T cells reduce acute lung injury fibroproliferation by decreasing fibrocyte recruitment. Am J Resp Cell Mol 2013;48:35-43.

24 Burnham EL, Janssen WJ, Riches DW, Moss M, Downey GP: The fibroproliferative response in acute respiratory distress syndrome: mechanisms and clinical significance. Eur Respir J 2014;43:276-285.

25 Li L, Zhang H, Min D, Zhang R, Wu J, Qu H, Tang Y: Sox9 activation is essential for the recovery of lung function after acute lung injury. Cell Physiol Biochem 2015;37:1113-1122.

26 Pilling D, Roife D, Wang M, Ronkainen SD, Crawford JR, Travis EL, Gomer RH: Reduction of BleomycinInduced Pulmonary Fibrosis by Serum Amyloid P. J Immunol 2007;179:4035-4044.

27 Quesnel C, Piednoir P, Gelly J, Nardelli L, Garnier M, Leçon V, Lasocki S, Bouadma L, Philip I, Elbim C, Mentré F, Soler P, Crestani B, Dehoux M: Alveolar fibrocyte percentage is an independent predictor of poor outcome in patients with acute lung injury. Crit Care Med 2012;40:21-28.

-28 Andersson-Sjoland A, Nihlberg K, Eriksson L, Bjermer L, Westergren-Thorsson G: Fibrocytes and the tissue niche in lung repair. Resp Res 2011;12:76. 


\section{Cellular Physiology Cell Physiol Biochem 2017;44:1526-1536 \begin{tabular}{ll|l} 
and Biochemistry 10.1159/000485647 & $\begin{array}{l}\text { Published online: December 04, 2017 The Author(s). Published by S. Karger AG, Basel } \\
\text { www.karger.com/cpb }\end{array}$ \\
\cline { 2 - 3 } &
\end{tabular} \\ Tai et al.: Effects of Cfb in ALI}

29 Rodriguez LG, Wu X, Guan JL: Wound-healing assay. Methods Mol Biol 2005;294:23-29.

30 Guide for the Care and Use of Laboratory Animals, 8th edition. Washington (DC): National Academies Press (US), 2011 gov/books/NBK54050.

31 Zhao YF, Luo YM, Xiong W, Ding W, Li YR, Zhao W, Zeng HZ, Gao HC, Wu XL: Mesenchymal stem cell-based FGF2 gene therapy for acute lung injury induced by lipopolysaccharide in mice. Eur Rev Med Pharmacol Sci 2015;19:857-865.

-32 Livak KJ, Schmittgen TD: Analysis of relative gene expression data using real-time quantitative PCR and the 2(-Delta Delta C(T)) Method. Methods 2001;25:402-408.

-33 Cross LJ, Matthay MA: Biomarkers in acute lung injury: insights into the pathogenesis of acute lung injury. Crit Care Clin 2011;27:355-377.

34 Mokra D, Kosutova P: Biomarkers in acute lung injury. Resp Physiol Neurobi 2015;209:52-58.

35 Keane M, Belperio J, Strieter R: Mediators and Inflammatory Cell Recruitment in Acute Lung Injury. Lung Injury: CRC Press [Book], 2005, vol 4, pp 111-149.

36 McCabe AJ, Dowhy M, Holm BA, Glick PL: Myeloperoxidase activity as a lung injury marker in the lamb model of congenital diaphragmatic hernia. J Pediatr Surg 2001;36:334-337.

37 Takaoka Y, Goto S, Nakano T, Tseng HP, Yang SM, Kawamoto S, Ono K, Chen CL: Glyceraldehyde-3-phosphate dehydrogenase (GAPDH) prevents lipopolysaccharide (LPS)-induced, sepsis-related severe acute lung injury in mice. Sci Rep-UK 2014;4:5204.

-38 Chen J, Lau YF, Lamirande EW, Paddock CD, Bartlett JH, Zaki SR, Subbarao K: Cellular immune responses to severe acute respiratory syndrome coronavirus (SARS-CoV) infection in senescent BALB/c mice: CD4+ T cells are important in control of SARS-CoV infection. J Virol 2010;84:1289-1301.

-39 Bao H, Gao F, Xie G, Liu Z: Angiotensin-Converting Enzyme 2 Inhibits Apoptosis of Pulmonary Endothelial Cells During Acute Lung Injury Through Suppressing MiR-4262 Cell Physiol Biochem 2015;37:759-767.

40 Liu S, Tang J, Huang L, Xu Q, Ling X, Liu J: Cordyceps Militaris Alleviates Severity of Murine Acute Lung Injury Through miRNAs-Mediated CXCR2 Inhibition. Cell Physiol Biochem 2015;36:2003-2011.

41 Fujiwara A1, Kobayashi H, Masuya M, Maruyama M, Nakamura S, Ibata H, Fujimoto H, Ohnishi M, Urawa M, Naito M, Takagi T, Kobayashi T, Gabazza EC,Takei Y, Taguchi O: Correlation between circulating fibrocytes, and activity and progression of interstitial lung diseases. Respirology 2012;17:693-698.

42 Deng X, Jin K, Li Y, Gu W, Liu M, Zhou L: Platelet-Derived Growth Factor and Transforming Growth Factor $\beta 1$ Regulate ARDS-Associated Lung Fibrosis Through Distinct Signaling Pathways. Cell Physiol Biochem 2015;36:937-946.

-43 Yin X, Liang Z, Yun Y, Pei L: Intravenous Transplantation of BMP2-Transduced Endothelial Progenitor Cells Attenuates Lipopolysaccharide-Induced Acute Lung Injury in Rats. Cell Physiol Biochem 2015;35:21492158. 